\author{
紫外線領域におけるイメージングプレートの感度応答特性 \\ 山下 洋, 甲藤 正人, 大西 俊四郎, 栗岡 豊 \\ 瀧川 靖雄 $*$, 黒澤 宏**, 山中 龍彦***, 宮原 譈二十,胡 \\ 近畿大学 理工学部（广 577-8502 大阪府東大阪市小若江 3-4-1) \\ $*$ 大阪電気通信大学 工学部 ( T 572-8530 大阪府寝屋川市初町 18-8) \\ **宮崎大学 工学部（干 889-2192 宮崎市学園木花台西 1-1） \\ ***大阪大学レーザー核融合研究センター（テ 565-0871 大阪府吹田市山田丘 2-6) \\ 富士写真フィルム (株) 機器事業部 SG（₹ 106-8620 東京都港区西麻布 2-26-30)
}

\title{
Response Characteristics of Imaging Plate in UV Region
}

\author{
Hiroshi YAMASHITA, Masahito KATTO, Shunshiro OHNISHI, Yutaka KURIOKA \\ Yasuo TAKIGAWA*, Kou KUROSAWA**, Tatsuhiko YAMANAKA*** \\ and Junji MIYAHARA \\ Department of Electrical Engineering, Kinki University, 3-4-1 Kowakae, Higashi-osaka, Osaka 577-8502 \\ *Department of Electronics, Osaka Electro-Communication University, 18-8 Hatsumachi, Neyagawa, Osaka 572-8530 \\ **Department of Electrical and Electronic Engineering, Miyazaki University \\ I-1 Gakuen, Kihanadai-nishi, Miyazaki 889-2192 \\ ***Institute of Laser Engineering at Osaka University, 2-6 Yamadaoka, Suita, Osaka 565-0871 \\ ${ }^{\dagger}$ Equipment Products Div., Fuji Photo Film Co., Ltd., 2-26-30 Nishiazabu, Minato-ku, Tokyo 106-8620
}

(Received May 25, 1998)

\begin{abstract}
An Imaging Plate (IP) has been developed as an image storing medium for use in medical X-ray diagnosis. We confirmed the IP to be a good medium not only for X-ray radiation but also for vacuum ultraviolet (VUV) and ultraviolet (UV) radiation. We found that the photo-stimulated luminescence (PSL) intensity showed a linear response to UV photon numbers in the range of $10^{4.5}$, and that showed saturation as the irradiated photon number increased. The sensitivity curve of the IP showed a peak at the wavelength of $200 \mathrm{~nm}$ and decreased at longer wavelengths. When the wavelength of the irradiated UV radiation was longer than $320 \mathrm{~nm}$, the PSL intensity was too low to detect with our system. This means that the cut-off wavelength of the sensitivity was measured as $310 \mathrm{~nm}$.
\end{abstract}

Key Words: Imaging plate, Photo-stimulable phosphor, Photo-stimulated luminescence, UV detector

\section{1.はじめに}

X線医療診断の記録媒体として, 輝尽性蛍光体をフィル ム上に塗布したイメージングプレート (Imaging Plate: IP) が開発され,市販されている. IPに一次励起光であるX線 を照射すると，その強度分布が電子密度として記録され る. その後, 二次励起光として赤色光を照射すると青色久 ペクトルの輝尽発光 (PSL: Photo-Stimulated Luminescence) が観測される.PSLの強度は電子密度, 寸なわち一次励起 光強度に比例し, PSLの強度分布を測定することで, 一次励 起光の強度分布情報の再生が可能である。

IPは高感度で低雑音, 広いダイナミックレンジと良好な 直線性, 広い有感面積と高い分解能, 高い計数効率, 現像処
理が不要であることなど, 優れた特長を有している，IPを 用いることで, 写真フィルムでは困難であった定量的な光 強度記録の評価を行うことができる。ささらにIPはX線だけ ではなく $\alpha$ 線, $\beta$ 線, $\gamma$ 線, 電子線, イオン線などのあらゆる 放射線に対して感度を有し1), 医療分野のみならず,放射線 を取り扱う他の多くの分野に拉いても, 検出器として応用 されている。

我々はIPが原理的には紫外領域から感度を有することに 着目し, IPを紫外光に対する光記録媒体として位置づけ た。これまでに,連続拉よびパルスの紫外線の強度記録が 可能であることを明らかにし2), 同一の測定システムおよ び同一の記録媒体でX線から紫外線にいたる広い範囲で, 輝尽性蛍光体の特長を活かした光強度の記録・再生が可

†現在の所属：一橋大学イノベーション研究センター（† 186-8603 東京都国立市中 2-1）

$\dagger$ Present Address: Institute of Innovation Research, Hitotsubashi University, 2-1 Naka, Kunitachi, Tokyo 186-8603 
能であることが実証された.

また, 紫外線領域に打けるIPの感度の波長依存性や飽和 特性については, 一次励起光源にシンクロトロン放射 $(\mathrm{SR})$ 光を使用して, 紫外線領域に拀けるIPのPSL感度スペクト ルを測定し, 波長 $200 \mathrm{~nm}$ と400nmに感度がピークを持つこ とを報告した ${ }^{2)}$ 。しかし, $400 \mathrm{~nm}$ 付近の感度スペクトルは 200nm付近でのスペクトルと形状がよく一致し,ささらに波 長が整数倍であることから,一次励起光に高次のスペクト ルが混入した可能性があった。またSR光はピコ秒パルス 出力であり,このため二光子吸収が影響していたことも考 えられた。また以前のデータでは, 長波長側の記録限界が 明確ではなかった。したがって, 我々は紫外領域に拀いて 連続光に対するIPの感度スペクトルについて, 再評価を行 うこととした。

本報告では, 輝尽性蛍光体を用いた記録媒体であるIPの 紫外光に対するPSL応答を測定するシステムの設計・製作 を行い,このシステムを用いて得られた紫外線領域の連続 光に対するIPの感度応答特性について述べる.

\section{2. 輝尽性蛍光体：イメージングプレート}

イメージングプレート (IP) では2価のユーロピウムイオ ン $\left(\mathrm{Eu}^{2+}\right)$ を添加して発光中心としたバリウムフロロハライ ド系輝尽性蛍光体 $\left(\mathrm{BaFBr}: \mathrm{Eu}^{2+}\right)$ が用いられている. IPの光 記録および再生の原理は以下のように説明されている3).

$\mathrm{Eu}^{2+}$ イオンはBa ${ }^{2+}$ イオンと置換して固溶する.この結晶 中には主として $\mathrm{F}^{-}$イオンまたは $\mathrm{Br}^{-}$イオンが欠けた 2 種類 の空格子点が存在する. $\mathrm{BaFBr}: \mathrm{Eu}^{2+}$ のエネルギー帯構造を Fig.1に示す.

はじめにX線などの一次励起光を輝尽性蛍光体に照射す ると, 荷電子带中に電子一正孔対が形成される. 正孔は発 光を促進するための活性体である2価のユーロピウムイオ ン $\left(\mathrm{Eu}^{2+}\right)$ に捕獲され, $\mathrm{Eu}^{3+}$ となる. 電子は伝導带へ励起さ れた後, 一部が陰イオン空格子点に捕獲され, ハロゲン空 格子一電子対, すなわちトセンターを生じる。この過程に より一次励起光の強度情報が Fセンターの密度として輝尽 性蛍光体に記録される。

Fセンターは赤色光に最大強度を持つ吸収を示す. 赤色

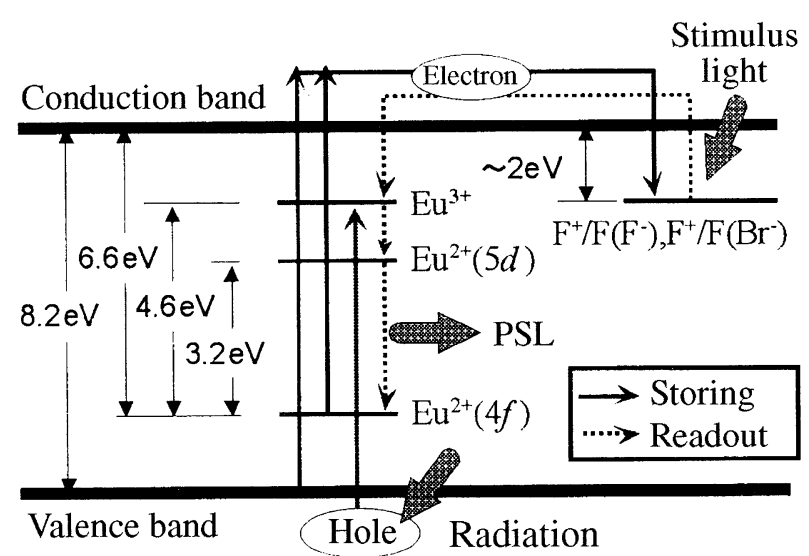

Fig.1 The energy diagram of $\mathrm{BaFBr}: \mathrm{Eu}^{2+}$ and PSL process. $^{3)}$
の二次励起光を吸収することで捕獲されていた電子は再 励起され, 伝導帯へ開放される。開放された電子は, $\mathrm{Eu}^{3+} に$ 捕獲されていた正孔と再結合し, $\mathrm{Eu}^{2+}$ の励起状態となる。 $\mathrm{Eu}^{2+}$ 淤起状態加基底状態に戻るときに波長 $\lambda=390 \mathrm{~nm}$ $(E=3.2 \mathrm{eV})$ の青色のPSLを生じる。これが, IPに記録され た情報が二次励起光により再生される過程である.PSLの 発光強度はFセンターの数に比例する。したがってPSL強 度は入射した放射線の強度に比例する. 二次励起光を二 次元的に走査し, 各点でのPSL強度を測定することで, 強度 分布情報の再生が可能である.

\section{3. 実験方法}

紫外線を照射した際にイメージングプレート(IP)から生 じる輝尽発光 (PSL)の強度を測定するために, 設計·製作し たシステムをFig.2に示す。

IPには医療X線撮影用に開発された標準型のものを使用 した，市販されている標準型のIPはBaFBr:Eu地層がプラス チック膜により保護されているが,この保護膜が紫外光を 吸収するため, 本実験においては取り除いたものを使用し た。

一次励起光としては, 重水素ランプ(江東電気 (株), F2763-3) と分光器 (光研工業 (株), SG-100)を組み合わせ, 単 色化した紫外光を利用した。紫外光は, コンピュータ(日本 電気(株)，PC9801）により制御されたシャッターを通し, 一定の時間だけIP上に照射される。波長は分光器により $190 \mathrm{~nm}$ から400nmまで変化させた。照射光子数はシャッ ターの開放時間を変化させることによって增減した。ま た, 分光器からの出力に高次の回折光が混入し, IP上に照射 されるのを防ぐため, 紫外光遮断フィルター(東芝硝子 (株), UV-25,UV-31）を併用した。紫外光の出力強度はフォ トダイオードによって測定し,フォトダイオードの分光感 度特性を用いて較正することにより,その絶対值を求め た。

紫外線をIPに照射した後, 波長 $635 \mathrm{~nm}$, 出力 $2 \mathrm{~mW}$ の半導体 レーザー((株)オーディオテクニカ, SU-30C)光をレンズに より集光し照射する. 発生したPSLは, 半導体レーザーの

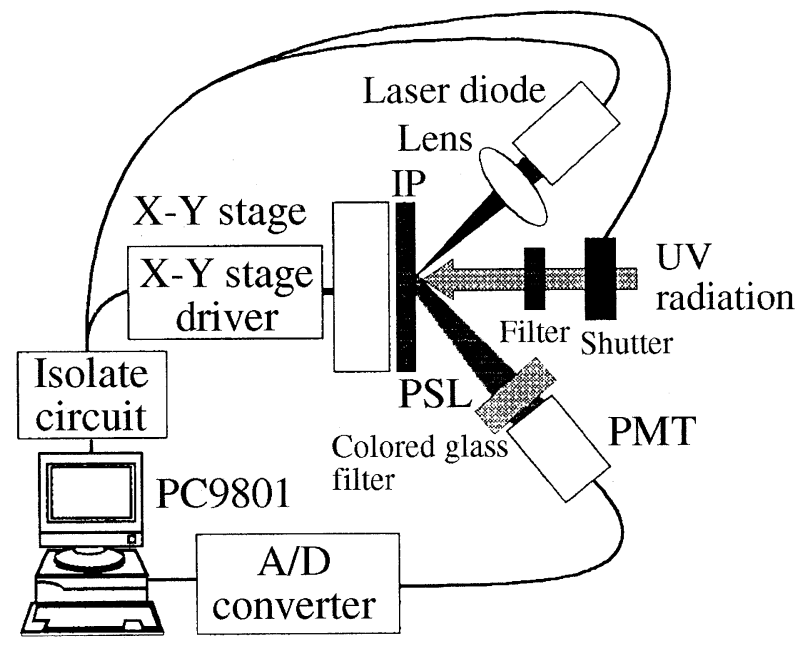

Fig.2 PSL intensity measurement system. 
散乱光を取り除くために挿入された色ガラスフィルター (東芝硝子 (株), C-40C) を通して, 光電子増倍管 $(\mathrm{PMT})$ で受 光する.PMTにはPSLの青色光に対する感度が高く, 半導 体レーザーの赤色光に対する感度が低い特性を持つR1635 (浜松ホトニクス(株))を使用した.PMTの出力はサンプ リング周期 $29 \mu \mathrm{s} て ゙ A / D$ 変換され, 時系列の 1600 個の $12 \mathrm{bit}$ ジタル信号としてコンピュータに読み込まれ, その総和が PSL強度として記録される。

\section{4. 結果および検討}

\section{1 輝尽発光強度特性}

一次励起光として照射する紫外光の波長を190nmから 400nmとしたときに,イメージングプレート(IP)からの輝 尽発光 (PSL) 強度を測定した結果の一部をFig.3に示す。横 軸は各波長の紫外光における単位面積あたりの照射光子 数, 縦軸はPSL強度である。

PSL強度は紫外光の照射光子数に対して, 最大で約4.5桁 にわたり線形応答を示し, 照射光子数を増加させるとPSL 強度の傾きが小さくなり, 飽和傾向を示すことが明らかと なった。また, 同じ光子数を照射した場合, 波長が長くな るとPSL強度が低下していることがわかる．設計・製作し た測定システムにおけるノイズの変動は, Fig.3のPSL強度 で1に相当するため, 1よりも小さなPSL強度は検出できな い.つまり, 波長が310nmより長波長の紫外光を照射した 場合はPSL強度が測定限界以下となった。波長を $310 \mathrm{~nm}$ り長くした場合でも, 高強度の紫外線を照射し, さらにPSL の受光効率を改善することでPSL応答は観測される。しか し感度は波長 $200 \mathrm{~nm}$ のとの $10^{-6}$ 以下となり,かなり小さな 值となる，我々の装置では波長310nmまで感度を確認でき たが, 実用上は波長300nm付近がPSL応答の長波長側のカッ トオフ波長である.

\section{2 感度特性}

感度を単位照射光子数あたりのPSL強度として定義し, Fig.3に一部を示した実験の結果から, 波長に対するIPの感 度特性を求めた。その結果をFig.4に示す。設計・製作し

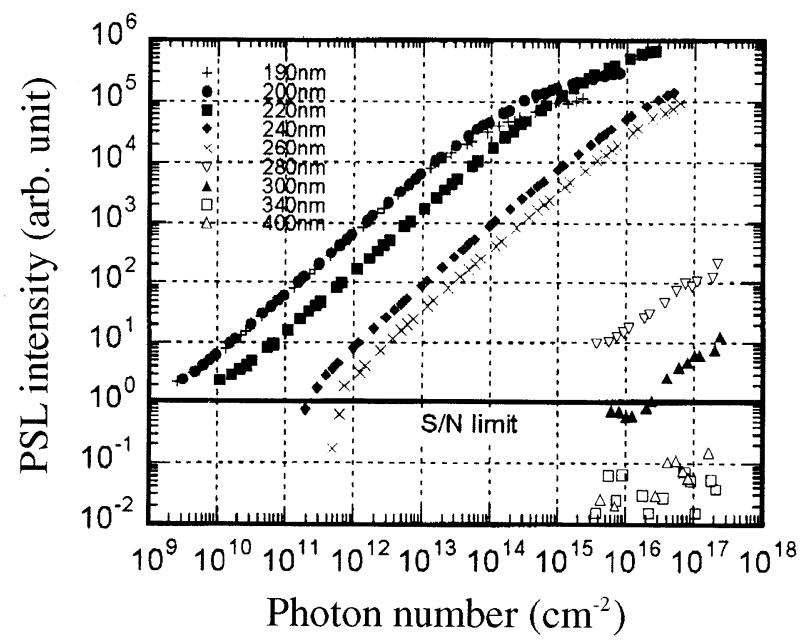

Fig.3 PSL intensity from IP with UV excitation, plotted as photon numbers.

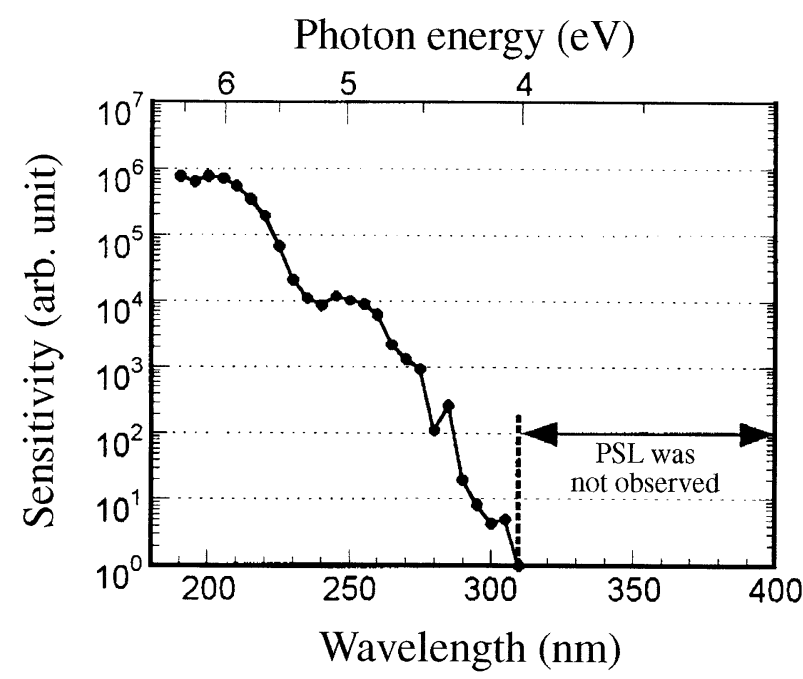

Fig.4 Sensitivity characteristics of IP in UV region, plotted as a function of irradiated UV wavelength.

た測定システムでは, 波長が310nmよりも長くなるとPSL強 度が測定限界以下となる。したがって, Fig.4においては, 波 長が310nmのときの感度を1として, 各波長での相対感度を 示した。

Fig.4より, IPの感度は波長が200nm付近のときに高く， 240nmまで波長が長くなるにしたがって低下寸ることがわ かる。また, 波長が240nmから260nmの間は感度がほぼ一 定となり,さらに長波長側になると波長が長くなるに従っ て低下する。

IPの感度は紫外光により電子が伝導帯へ遷移する確率 と, 光の侵入長の積によって決定される. IPの母材である BaFBr:Eu+の禁制帯幅は8.3eV(波長：150nm)であり，波長 が150nmよりも長くなると電子の遷移確率が低くなり, 励 起される電子の数が減少する。このため, Fセンターに捕 獲される電子の密度が低下し, 感度も低下する. 200nm付 近では, $\mathrm{Eu}^{2+}$ から伝導帯への遷移が6.6eV $(190 \mathrm{~nm})$ であるこ とから ${ }^{4)}$, 電子の遷移確率が大きくなり, 感度が高くなる. また波長が250nmよりも長い光に対しては, $\mathrm{BaFBr}: \mathrm{Eu}^{2+}$ の

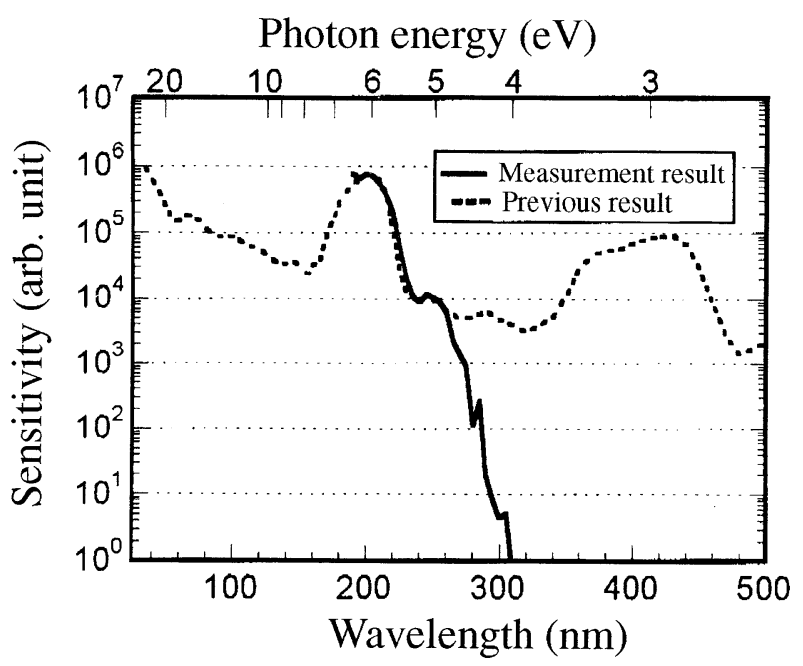

Fig.5 Comparison of sensitivity characteristics. The continuous line shows the experimental result measured in this paper, and the broken one is the previous one. ${ }^{2)}$ 
吸光度が急激に大きくなる4).このため光のBaFBr:Eu ${ }^{2+} に$ 対する侵入長が短くなり, 輝尽発光に寄与し得る $\mathrm{BaFBr}$ : $\mathrm{Eu}^{2+}$ 層の厚さが減少する。したがって250nmよりも長波長 側での感度は急激に減少する。

Fig.5に, 今回の測定により得られた感度特性と, 以前に 報告した感度特性 2 を比較のために示す。 $250 \mathrm{~nm}$ よりも短 波長側の特性は非常によく一致しているが, 250nmよりも 長波長領域では大きく異なっている，以前の測定におい て, 感度は波長200nmおよび400nmにピークを持つ. 特性

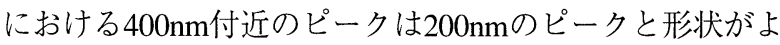
く一致し,さらに波長が整数倍であることから, 励起光源 に高次の回折光が混入し,感度が高く評価されていた可能 性がある.また, SR光は数ピコ秒のパルス幅を持つ短パル ス光であることから, 2 光子吸収による遷移の寄与が考えら れる. Fig.4, 5より紫外線領域における連続光源に対する 感度スペクトルが200nmにピークを有することがわかる。

\section{3 飽和光子数特性}

Fig.3に一部を示した実験の結果から,照射光子数に対す るPSL強度の傾きが1より小さくなる光子数を飽和光子数 として求め, 波長に対してプロットしたものをFig.6に示 す． 飽和光子数は紫外光の波長が190nmであるときに最も 少なく,230nmまで波長が長くなるにしたがって増加する ことがわかる。また, 波長が230nmから260nmの間ではほ ぼ一定となり，さらに長波長側になると波長が長くなるに したがって増加している。

飽和光子数は 1 個の電子を励起するために必要な光子数, つまりは電子の遷移確率の逆数と, 光の侵入長の積によっ て決定される。波長が200nmから230nmの領域では, 波長 が長くなるに従い電子の遷移確率が低くなり，したがって 1個の電子を励起するために必要な光子数が増加する。さ らに, $\mathrm{BaFBr}: \mathrm{Eu}^{2+}$ の吸光度が小さくなり ${ }^{4)}$, 侵入長が長くな る.このために波長が長くなるにしたがって飽和光子数 は増加する。230nmから $250 \mathrm{~nm}$ の波長域では, 電子の遷移 確率が長波長になるに従い低下する。しかし, $\mathrm{BaFBr}: \mathrm{Eu}^{2+}$ の吸光度はほぼ一定であることから ${ }^{4)}$, 飽和光子数の変化 も小さくなる．250nmより長い波長域では, IPの吸光度が 大きくなり4), 光子の侵入長は短くなるが, 電子の遷移確率 が低下することから, 1 個の電子を励起するために必要な光 子数が増加する. したがって, 飽和光子数も波長に伴って 増加する。

\section{5. おわりに}

本研究では,イメージングプレート (IP)の輝尽発光

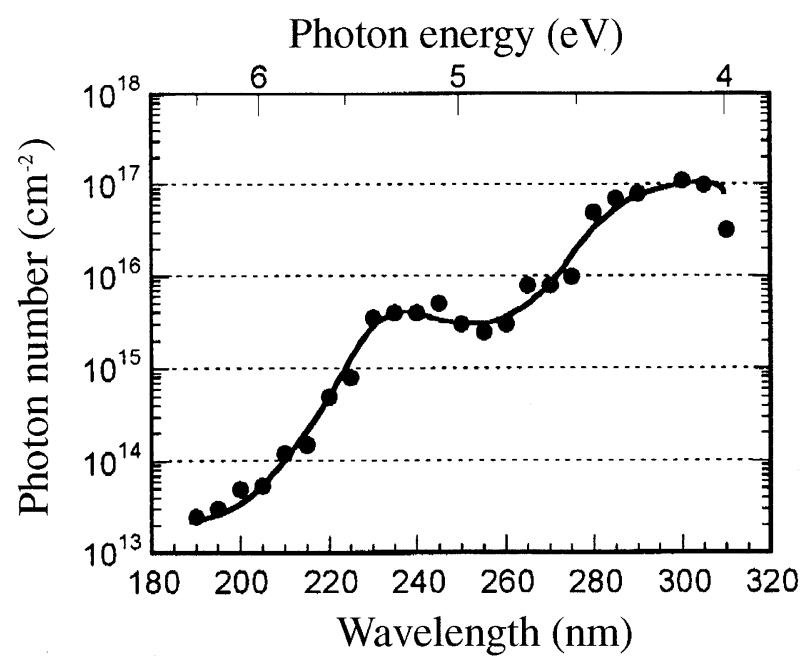

Fig.6 Saturated photon number of IP, plotted as a function of irradiated UV wavelength.

(PSL) 強度を測定するシステムを設計・製作し，このシス テムを用いて紫外線を照射したときに観測されるPSL強度 を測定した。この結果, PSL応答は最大で約4.5桁にわたる 直線応答を示し, さらに紫外線の照射強度を増加させると 飽和傾向を示すことが明らかになった，感度特性につい ては, 波長が200nmのときに感度が最大となり, 波長が長く なると感度が低下する。また250nm付近に感度が一定とな る領域が存在する．飽和光子数はIPに対して高感度の波長 に対しては減少し, 感度が低くなると増加する．波長が $310 \mathrm{~nm}$ よ長波長になるとPSL強度が最大感度の $10^{-6}$ 以下 と非常に小さくなり,この領域がIPにおける, 実用的な長波 長側のカットオフ波長であることが明らかとなった。

\section{謝 辞}

本研究は大阪大学レーザー核融合研究センターとの共 同研究として行われたものであり,同センター長三間 國興 教授に謝意を表します。

\section{参考文献}

1) 宮原 諒二：固体物理 30 (1995) 674.

2) 黒澤 宏, 甲藤 正人, 瀧川 靖雄, 佐々木 亘：レーザー研究 22 (1994) 734.

3）宮原 諒二, 雨宮慶幸, 松下 正：日本物理学会誌 45 （1990） 398.

4) Y. Iwabuchi, N. Mori, K. Takahashi, T. Matsuda, and S. Shionoya: Jpn. J. Appl. Phys. 33 (1994) 178. 